\title{
Defining the optimal cut-off values for liver enzymes in diagnosing blunt liver injury
}

Tomohide Koyama ${ }^{1,3^{*}}$, Hirohisa Hamada ${ }^{2}$, Masamichi Nishida² ${ }^{2}$ Paal A. Naess ${ }^{3}$, Christine Gaarder ${ }^{3}$ and Tetsuya Sakamoto ${ }^{1}$

\begin{abstract}
Background: Patients with blunt trauma to the liver have elevated levels of liver enzymes within a short time post injury, potentially useful in screening patients for computed tomography $(\mathrm{CT})$. This study was performed to define the optimal cut-off values for serum aspartate aminotransferase (AST) and alanine aminotransferase (ALT) in patients with blunt liver injury diagnosed with contrast enhanced multi detector-row CT (CE-MDCT).

Methods: All patients admitted from May 2006 to July 2013 to Teikyo University Hospital Trauma and Critical Care Center, and who underwent abdominal CE-MDCT within $3 \mathrm{~h}$ after blunt trauma, were retrospectively enrolled. Using receiver operating characteristic (ROC) curve analysis, the optimal cut-off values for AST and ALT were defined, and sensitivity and specificity were calculated.

Results: Of a total of 676 blunt trauma patients 64 patients were diagnosed with liver injury (Group LI+) and 612 patients without liver injury (Group LI-). Group LI+ and LI- were comparable for age, Revised Trauma Score, and Probability of survival. The groups differed in Injury Severity Score [median 21 (interquartile range 9-33) vs. 17 (9-26) $(p<0.01)$ ]. Group LI+ had higher AST than LI- [276 (48-503) vs. 44 (16-73); $p<0.001$ ] and higher ALT [240 (92-388) vs. 32 (16-49); $p<0.001$ ]. Using ROC curve analysis, the optimal cut-off values for AST and ALT were set at $109 \mathrm{U} / \mathrm{l}$ and $97 \mathrm{U} / \mathrm{l}$, respectively. Based on these values, AST $\geq 109 \mathrm{U} / \mathrm{l}$ had a sensitivity of $81 \%$, a specificity of $82 \%$, a positive predictive value of $32 \%$, and a negative predictive value of $98 \%$. The corresponding values for ALT $\geq 97 \mathrm{U} / \mathrm{I}$ were 78 , 88,41 and $98 \%$, respectively, and for the combination of AST $\geq 109 \mathrm{U} / \mathrm{I}$ and/or ALT $\geq 97 \mathrm{U} / \mathrm{I}$ were 84, 81, 32, $98 \%$, respectively.
\end{abstract}

Conclusions: We have identified AST $\geq 109 \mathrm{U} / \mathrm{l}$ and ALT $\geq 97 \mathrm{U} / \mathrm{l}$ as optimal cut-off values in predicting the presence of liver injury, potentially useful as a screening tool for CT scan in patients otherwise eligible for observation only or as a transfer criterion to a facility with CT scan capability.

Keywords: Blunt liver trauma, Liver transaminase, CE-MDCT, ROC curve analysis, Youden index

\section{Background}

The liver is one of the most commonly injured abdominal organs and is reported in approximately $5 \%$ of all trauma patients $[1,2]$. Since computed tomography (CT) was introduced in trauma evaluation in the early 1980s [3], patients with a history of significant trauma who are

\footnotetext{
*Correspondence: t-koyama@office.nifty.jp

${ }^{1}$ Department of Emergency Medicine, Teikyo University Hospital, 2-11-1

Kaga, Itabashi, Tokyo, Japan

Full list of author information is available at the end of the article
}

hemodynamically normal(ized) will undergo CT if available. Although CT has become the "gold standard" for detecting injuries to the intraabdominal solid organs, CT is not always present in every institution worldwide, even in high-income countries such as Japan. Additionally, there is evidence demonstrating that CT scanning carries a risk of causing malignancies and thus should be avoided when possible [4].

Ultrasound has significant limitations as a diagnostic tool since the overall sensitivity is as low as $72 \%$ for 
detecting blunt liver injury based on detection of free fluid, parenchymal injury or both [5].

On that background the serum biomarkers such as serum aspartate aminotransferase (AST) and alanine aminotransferase (ALT) have received attention as markers of liver injury. Several previous studies have tried to define the cut-off value for AST and/or ALT in blunt liver injury [6-15]. However, the results have been conflicting. We infer that the variations might be related to biases such as the population studied, the detection method for liver injury, timing of blood sampling, and statistical analysis method.

The purpose of this study was to establish optimal cutoff values for AST and ALT in patients with blunt liver injury. Such values could be potentially useful to indicate the need for CT scan in patients otherwise eligible for observation only or as a transfer criterion to a facility with CT scan capability.

\section{Methods}

Based on the results from a previous study from our institution published in a Japanese journal [16], all blunt trauma patients admitted to Teikyo University Hospital Trauma and Critical Care Center who underwent initial evaluation with abdominal contrast enhanced (CE) multi detector-row computed tomography (MDCT) within $3 \mathrm{~h}$ after injury, were retrospectively enrolled between May 2006 and July 2013. This study was approved by Teikyo University Hospital Ethics Committee.

Admission data collected included the following: age, gender, mechanism of injury, Glasgow Coma Scale (GCS), and Revised Trauma Score (RTS). All patients included in the study were followed throughout their hospital stay. Injury Severity Score (ISS), Probability of survival (Ps), interventions (laparotomy and/or angioembolization (AE)), liver related complications, and mortality were recorded.

The admission values of AST and ALT were measured using LABOSPECT 008 Automatic Analyzer or Clinical Analyzer Model 7600 (both Hitachi High- Technologies Corporation (Corp.), Tokyo, Japan).

Hemodynamically normal patients, on admission or after initial resuscitation, underwent CE-MDCT if at least one of the following criteria was fulfilled: (1) complaint of severe abdominal pain, (2) peritonism, (3) external signs of abdominal injuries, (4) presence of hematuria, melena or hematemesis, (5) abnormal radiographic findings commonly associated with abdominal injuries (intraperitoneal free air, lower rib fracture, pelvic fracture, or lumbar fracture) (6) positive abdominal focused assessment with sonography in trauma (FAST), (7) acute anemia with hemoglobin $<10 \mathrm{~g} / \mathrm{dl}$, (8) impaired consciousness due to suspected traumatic brain injury.
CT was performed using a 64-slice MDCT scanner (Aquilion 64, TSX-101A/HA, Toshiba Medical Systems Corp., Japan) with intravenous contrast material (Omnipaque 300 injection syringe, Daiichi Sankyo Company (Co.), Limited (Ltd.), Tokyo, Japan or Oypalomin 300 injection syringe, Fuji Pharma Co., Ltd., Toyama, Japan) unless the patient was known to suffer from chronic kidney disease.

The liver injury was defined from CE-MDCT scans based on Organ Injury Scale (OIS, 1994 revision) described by the American Association for the Surgery of Trauma [17]. Attending staff reviewed the CE-MDCT at the following morning conference, and consensus was reached.

Statistical analysis was performed using the IBM SPSS Statistics version 22 for MacOSX [International Business Machines Corp., New York, United States of America (USA)] and the Microsoft Excel for Mac 2011 (Microsoft Corp., Washington, USA). Categorical variables were presented as medians and underwent Chi square test. Continuous variables were presented as median with interquartile range (IQR), and subjected to the MannWhitney $\mathrm{U}$ test. All $\mathrm{p}$ values reported are two-sided, and $p$ values $<0.05$ were considered to indicate statistical significance.

Receiver operating characteristic (ROC) curve analysis was performed to define the optimal cut-off values for AST and ALT [18]. Two additional analysis methods were used to determine the optimal cut-off values objectively. The first method was 'The closest to $(0,1)$ criteria', in this paper called 'upper-left (UL) index', and represents the values at the shortest distance from the upper left corner to the ROC curve. The second was 'the Youden index', which describes the maximum vertical distance between the ROC curve and the diagonal or chance line [19]. After determining the optimal cut-off values for AST and ALT with these methods, sensitivity and specificity were calculated.

\section{Results}

During the study period, 1856 trauma patients were admitted. Of the 1643 patients with blunt trauma, 676 patients underwent abdominal CE-MDCT within $3 \mathrm{~h}$ after injury. Based on CE-MDCT scans, 64 patients were diagnosed with liver injury (Group LI+) and 612 patients without liver injury (Group LI-) (Fig. 1).

Group LI+ consisted of nine patients with OIS grade I injuries, 30 patients with grade II injuries, 18 with grade III injuries, 6 with grade IV injuries, and 1 with grade V injury. In Group LI+, 9 (14.1\%) patients had isolated liver injury and $55(85.9 \%)$ patients had combined injuries. Of the 55 patients with combined injuries, 17 patients had head injury, 12 had facial injury, 45 had chest injury, 21 


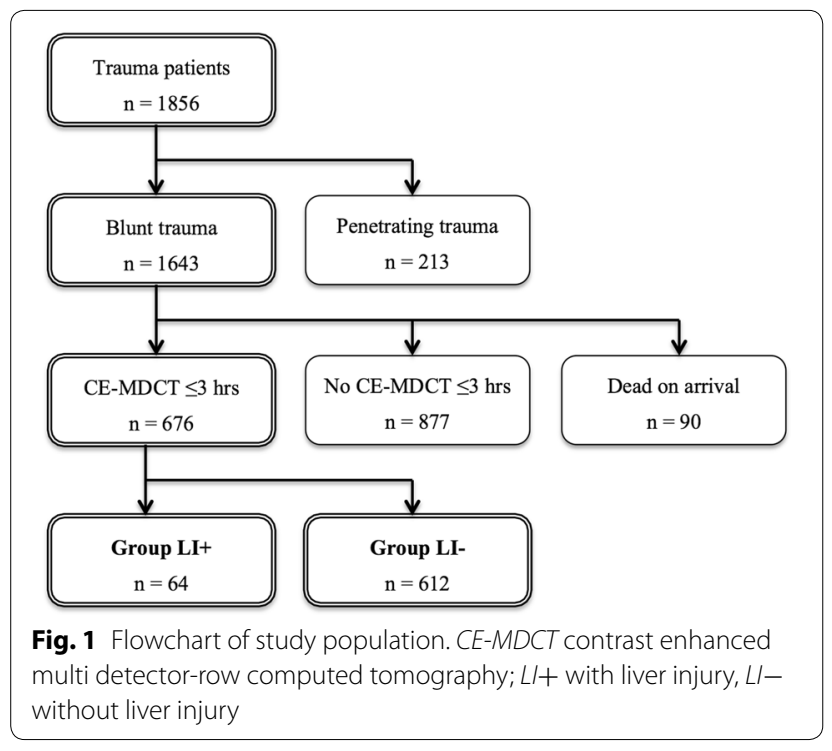

had other abdominal injuries, 12 had pelvic injury, $18 \mathrm{had}$ spinal injury, and 20 had extremity injury.

In Group LI+, 11 (17.2\%) patients underwent $\mathrm{AE}$ and $5(7.8 \%)$ underwent laparotomy. A total of $5(7.8 \%)$ patients developed liver related complications. Two patients had biloma, one was treated with percutaneous drainage, and one resolved spontaneously. One patient had bile leakage treated with surgical drainage, one patient had a pseudo-aneurysm treated with $\mathrm{AE}$, and one patient had cholecystitis treated with percutaneous transhepatic gallbladder drainage.

Five $(7.8 \%)$ patients in Group LI+ died from massive hemorrhage, none of them liver-related; three patients with pelvic fracture with retroperitoneal hematoma, and two patients with chest injury.

Characteristics of this study population are presented in Table 1. Group LI+ and LI- were comparable for age,
RTS, and Ps. The groups differed in ISS [median 21 (IQR 9-33) vs. 17 (9-26); p < 0.01]. Group LI+ had higher AST than LI- [276 (48-503) vs. 44 (16-73); p < 0.001] and higher ALT [240 (92-388) vs. 32 (16-49); p < 0.001].

ROC curve analysis for AST and ALT was performed where the area under ROC curve (AUC) of AST was 0.88 (95\% confidence interval (CI) 0.83-0.92) and of ALT was 0.88 (95\% CI 0.83-0.94) (Fig. 2). With these analyses, the optimal cut-off values for AST was set at $109 \mathrm{U} / \mathrm{l}$ (UL index 0.26, Youden index 0.63) (Fig. 3) and ALT were set at $97 \mathrm{U} / \mathrm{l}$ (UL index 0.25, Youden index 0.67) (Fig. 4), and the calculated sensitivity and specificity based on these cut-off values are shown in Table 2 .

Ten patients with AST $<109 \mathrm{U} / \mathrm{l}$ and ALT $<97 \mathrm{U} / \mathrm{l}$ had liver injury diagnosed on CE-MDCT; one OIS grade I injury, eight grade II, and one grade III. None of these ten patients required any interventions for their liver injury, and didn't suffer any liver related complication or death.

\section{Discussion}

In the present study, blood samples were drawn immediately upon arrival and CT scans performed within $3 \mathrm{~h}$ post injury. Based on these strict criteria and the use of UL index and Youden index, we defined AST $\geq 109 \mathrm{U} / \mathrm{l}$ and ALT $\geq 97 \mathrm{U} / \mathrm{l}$ as the optimal cut-off values in predicting the presence of blunt liver injury.

Shadev et al. [12] used ROC curve analysis to define cut off values for AST and ALT in patients with blunt liver injury verified by ultrasound, diagnostic peritoneal lavage, nuclear scanning, laparotomy or CT-scan. Moreover, $50 \%$ of the patients in the non-liver injury group were identified based on physical examination alone. The method for defining the optimal cut-off values for AST and ALT was not described.

In a study by Tian et al. [13] the cut-off values were set at AST $\geq 113 \mathrm{U} / \mathrm{l}$ and ALT $\geq 57 \mathrm{U} / \mathrm{l}$ by using ROC curve analysis. To identify the liver injury, CT and laparotomy

Table 1 Characteristics of the study population

\begin{tabular}{lcccc}
\hline & All $(\mathbf{n}=\mathbf{6 7 6})$ & LI+ $(\mathbf{n}=\mathbf{6 4 )}$ & LI- $(\mathbf{n}=\mathbf{6 1 2})$ & $\mathbf{p}$ value \\
\hline AST & $48(31-106)$ & $276(48-503)$ & $44(16-73)$ & $32(16-49)$ \\
ALT & $36(22-69)$ & $240(92-388)$ & $17(9-26)$ & $<0.001$ \\
ISS & $17(9-26)$ & $21(9-33)$ & $14(13-15)$ & $<.001$ \\
GCS & $15(13-15)$ & $15(14-15)$ & $7.84(7.37-7.84)$ & 0.01 \\
RTS & $7.84(6.90-7.84)$ & $7.84(7.37-7.84)$ & $97.4(92.9-100)$ & 0.67 \\
PS & $97.0(89.5-99.2)$ & $95.7(88.1-100)$ & $46(29-63)$ & 0.19 \\
Age & $46(29-63)$ & $40(23-57)$ & $426(69.6)$ & 0.17 \\
Male gender, $n(\%)$ & $462(68.3)$ & $56(56.3)$ & $53(8.7)$ & 0.03 \\
Mortality, $n(\%)$ & $58(8.6)$ & $5(7.8)$ & 0.82 \\
\hline
\end{tabular}

Values are given as median (IQR) where not stated otherwise

LI+ with liver injury, LI - without liver injury, AST aspartate aminotransferase, ALT alanine aminotransferase, ISS injury severity score, GCS Glasgow coma scale, RTS revised trauma score, $P$ s probability of survival 


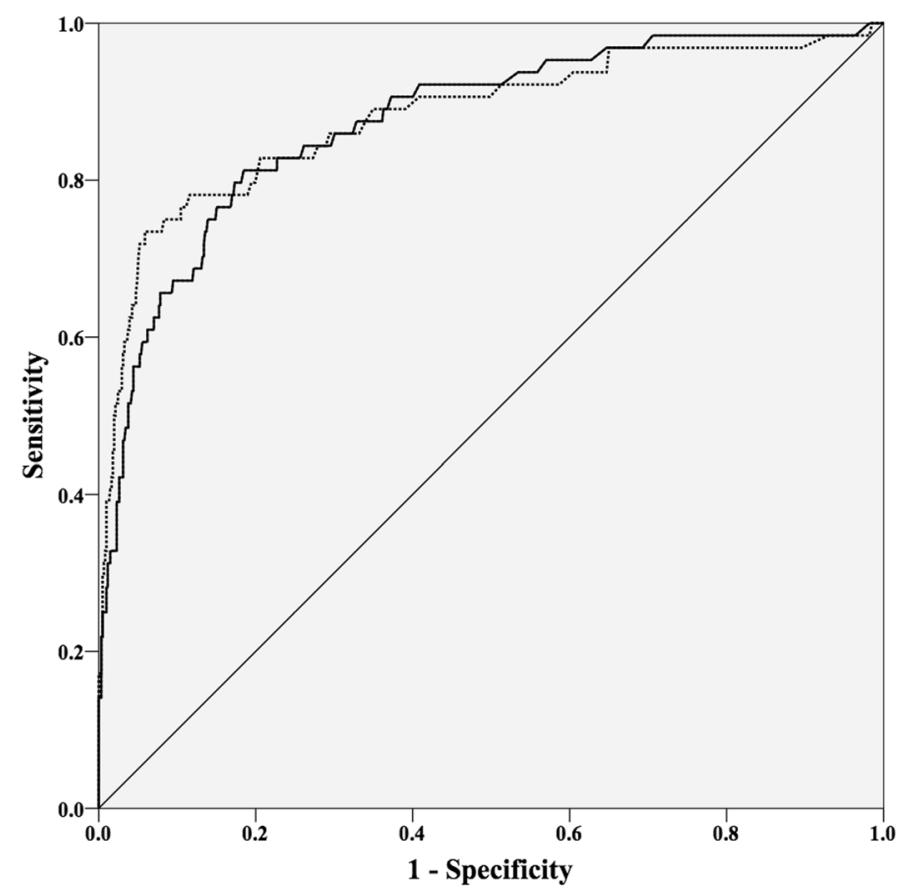

-AST …...ALT

AUC (AST) : 0.88

AUC (ALT) : 0.88

Fig. 2 ROC curve of AST and ALT. AST aspartate aminotransferase, ALT alanine aminotransferase, ROC receiver operating characteristic, AUC area under the curve

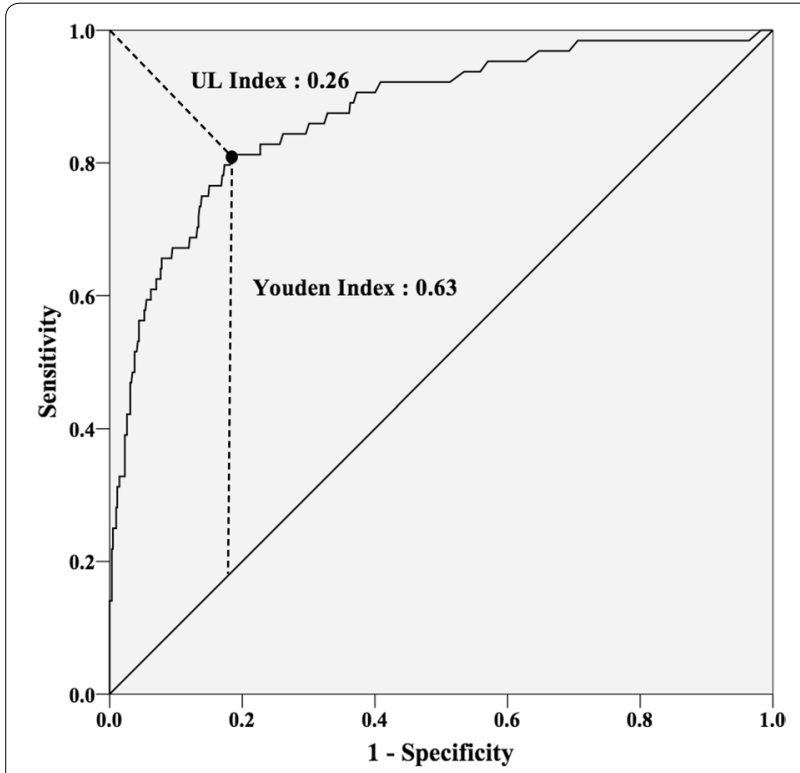

Fig. 3 ROC curve of AST with UL index and Youden index. ROC receiver operating characteristic, AST aspartate aminotransferase, UL upper-left

were used and blood samples were drawn up to $24 \mathrm{~h}$ after injury. Moreover, the values of AUC for AST and ALT and the method for defining the optimal cut-off values were not described in their study.

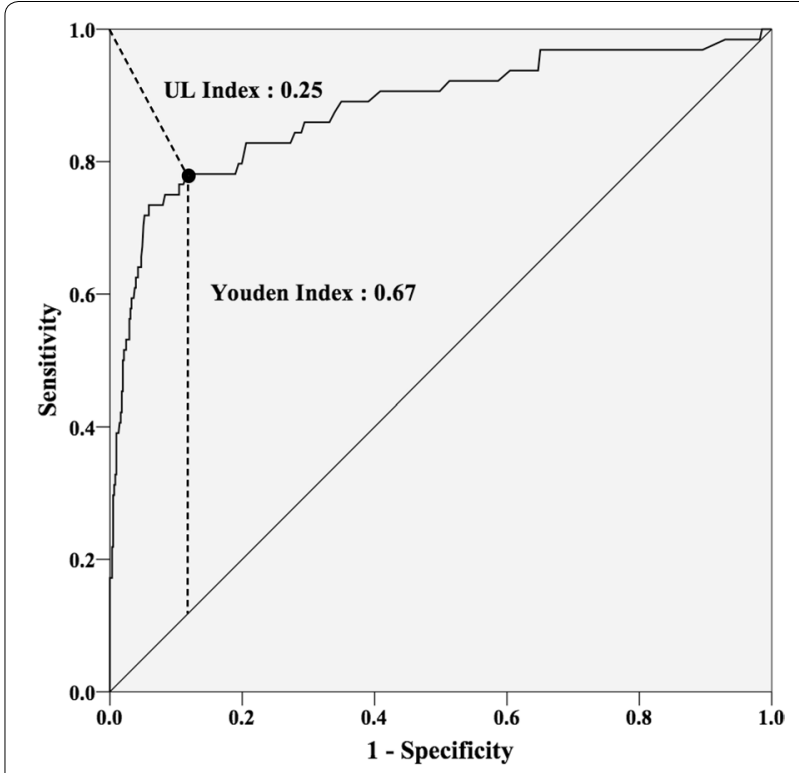

Fig. 4 ROC curve of ALT with UL index and Youden index. ROC receiver operating characteristic, ALT alanine aminotransferase, UL upper-left

Tan et al. [14] set the cut-off values for AST $\geq 83 \mathrm{U} / \mathrm{l}$ and ALT $\geq 64 \mathrm{U} / \mathrm{l}$ in a series of 99 patients of whom 55 patients were LI+ defined by $\mathrm{CT}$ and laparotomy. In a case-control study, Lee et al. [15] set the cut-off values 
Table 2 Results of the optimal cut-off values of AST and ALT

\begin{tabular}{lllll}
\hline Cut-off values & Sensitivity (\%) & Specificity (\%) & PPV (\%) & NPV (\%) \\
\hline AST $\geq 109$ & 81 & 82 & 32 & 98 \\
$A L T \geq 97$ & 78 & 88 & 41 & 98 \\
AST $\geq 109$ and/or & 84 & 81 & 32 & 98 \\
$A L T \geq 97$ & & & & \\
\hline
\end{tabular}

$L I+$ with liver injury, $L I-$ without liver injury, AST aspartate aminotransferase, $A L T$ alanine aminotransferase, $P P V$ positive predictive value, NPV negative predictive value

at $\mathrm{AST} \geq 100 \mathrm{U} / \mathrm{l}$ and $\mathrm{ALT} \geq 80 \mathrm{U} / \mathrm{l}$. They compared 42 LI+ patients and $42 \mathrm{LI}-$ patients based on findings on CT evaluation. Statistical analysis was done to determine whether AST and ALT could predict the liver injury. However, in none of those studies any attempt to define the optimal cut-off values for AST and ALT were performed.

As many as $10 \mathrm{LI}+$ patients presented with AST $<109 \mathrm{U} / \mathrm{l}$ and ALT $<97 \mathrm{U} / \mathrm{l}$. However, they were all treated by observation alone and suffered no complications. Thus, the cut-off values in the present study seem to represent clinically relevant thresholds for further diagnostics, especially in a remote and/or resource limited institution, to decide whether a patient is eligible for observation alone without jeopardizing the patient's safety or require closer monitoring and further investigations.

In the aforementioned study of Hamada et al. [16] the optimal cut-off values for AST and ALT were defined to be $166 \mathrm{U} / 1$ and $130 \mathrm{U} / \mathrm{l}$, respectively. We assume that the lower cut-off values for AST and ALT in the present study can be attributed to the higher detection capability of the MDCT compared to the one achievable in the single detector-row computed tomography [20-22] as used in the previous study.

There are some limitations to this study in addition to its retrospective nature. The number of LI+ patients was relatively small. Additional studies are required to verify whether the optimal cut-off values defined in a single urban center in Asia are applicable worldwide.

\section{Conclusions}

In conclusion, we have identified AST $\geq 109 \mathrm{U} / \mathrm{l}$ and ALT $\geq 97 \mathrm{U} / \mathrm{l}$ as optimal cut-off values for predicting the presence of liver injury in blunt trauma, potentially useful as a screening tool for CT scan in patients otherwise eligible for observation only or as a transfer criterion to a facility with CT scan capability.

\section{Authors' contributions}

TK, HH, MN, TS conceived the study. TK, HH collected and analyzed the data. TK, PAN, CG wrote the manuscript, which $\mathrm{HH}, \mathrm{MN}$, TS critically revised, and all authors read and approved the final manuscript.

\section{Author details}

Department of Emergency Medicine, Teikyo University Hospital, 2-11-1 Kaga, Itabashi, Tokyo, Japan. ${ }^{2}$ Department of Emergency Medicine, Toranomon Hospital, Tokyo, Japan. ${ }^{3}$ Department of Traumatology, Oslo University HospitalUlleval, Oslo, Norway.

\section{Acknowledgements}

We thank Teikyo University Medical Library for providing funds to support the open-access publication of this study.

\section{Competing interests}

The authors declare that they have no competing interests.

Received: 19 June 2015 Accepted: 14 January 2016

Published online: 25 January 2016

\section{References}

1. Croce MA, Fabian TC, Menke PG, Waddle-Smith L, Minard G, Kudsk $K A$, et al. Nonoperative management of blunt hepatic trauma is the treatment of choice for hemodynamically stable patients. Results of a prospective trial. Ann Surg. 1995;221(6):744-53.

2. Piper GL, Peitzman AB. Current management of hepatic trauma. Surg Clin North Am. 2010;90(4):775-85.

3. Federle MP, Goldberg HI, Kaiser JA, Moss AA, Jeffrey RB Jr, Mall JC. Evaluation of abdominal trauma by computed tomography. Radiology. 1981;138(3):637-44.

4. Brenner DJ, Hall EJ. Computed tomography-an increasing source of radiation exposure. N Engl J Med. 2007:357(22):2277-84.

5. Richards JR, McGahan JP, Pali MJ, Bohnen PA. Sonographic detection of blunt hepatic trauma: hemoperitoneum and parenchymal patterns of injury. J Trauma. 1999:47(6):1092-7.

6. Oldham KT, Guice KS, Kaufman RA, Martin LW, Noseworthy J. Blunt hepatic injury and elevated hepatic enzymes: a clinical correlation in children. J Pediatr Surg. 1984;19(4):457-61.

7. Hennes HM, Smith DS, Schneider K, Hegenbarth MA, Duma MA, Jona JZ. Elevated liver transaminase levels in children with blunt abdominal trauma: a predictor of liver injury. Pediatrics. 1990;86(1):87-90.

8. Puranik SR, Hayes JS, Long J, Mata M. Liver enzymes as predictors of liver damage due to blunt abdominal trauma in children. South Med J. 2002;95(2):203-6.

9. Karam O, La Scala G, Le Coultre C, Chardot C. Liver function tests in children with blunt abdominal traumas. Eur J Pediatr Surg. 2007:17(5):313-6.

10. Stassen NA, Lukan JK, Carrillo EH, Spain DA, Norfleet LA, Miller FB, et al. Examination of the role of abdominal computed tomography in the evaluation of victims of trauma with increased aspartate aminotransferase in the era of focused abdominal sonography for trauma. Surgery. 2002;132(4):642-6.

11. Srivastava AR, Kumar S, Agarwal GG, Ranjan P. Blunt abdominal injury: serum ALT-A marker of liver injury and a guide to assessment of its severity. Injury. 2007;38(9):1069-74.

12. Sahdev P, Garramone RR Jr, Schwartz RJ, Steelman SR, Jacobs LM. Evaluation of liver function tests in screening for intra-abdominal injuries. Ann Emerg Med. 1991;20(8):838-41.

13. Tian Z, Liu H, Su X, Fang Z, Dong Z, Yu C, et al. Role of elevated liver transaminase levels in the diagnosis of liver injury after blunt abdominal trauma. Exp Ther Med. 2012:4(2):255-60.

14. Tan KK, Bang SL, Vijayan A, Chiu MT. Hepatic enzymes have a role in the diagnosis of hepatic injury after blunt abdominal trauma. Injury. 2009;40(9):978-83.

15. Lee WC, Kuo LC, Cheng YC, Chen CW, Lin YK, Lin TY, et al. Combination of white blood cell count with liver enzymes in the diagnosis of blunt liver laceration. Am J Emerg Med. 2010;28(9):1024-9.

16. Hamada H, Tagawa Y, Fujita T, Nishida M, Endo Y, Kobayashi K, et al. Cut-off values for AST and ALT as criteria for performing abdominal enhanced computed tomography (CT) in the diagnosis of blunt liver injury. J Jpn Assoc Acute Med. 2012;23:142-50 (Article in Japanese).

17. Moore EE, Cogbill TH, Jurkovich GJ, Shackford SR, Malangoni MA, Champion HR. Organ injury scaling: spleen and liver (1994 revision). J Trauma. 1995;38(3):323-4 
18. Hanley JA, MCNeil BJ. The meaning and use of the area under a receiver operating characteristic (ROC) curve. Radiology. 1982;143(1):29-36.

19. Perkins NJ, Schisterman EF. The inconsistency of "optimal" cutpoints obtained using two criteria based on the receiver operating characteristic curve. Am J Epidemiol. 2006;163(7):670-5.
20. Shanmuganathan K. Multi-detector row CT imaging of blunt abdominal trauma. Semin Ultrasound CT MR. 2004;25(2):180-204.

21. Hammerstingl RM, Vogl TJ. Abdominal MDCT: protocols and contrast considerations. Eur Radiol. 2005:15(Suppl 5):E78-90.

22. Aschoff AJ. MDCT of the abdomen. Eur Radiol. 2006;16(Suppl 7):M54-7.
Submit your next manuscript to BioMed Central and we will help you at every step:

- We accept pre-submission inquiries

- Our selector tool helps you to find the most relevant journal

- We provide round the clock customer support

- Convenient online submission

- Thorough peer review

- Inclusion in PubMed and all major indexing services

- Maximum visibility for your research

Submit your manuscript at www.biomedcentral.com/submit
(OioMed Central 